\title{
EFFECT OF CURCUMA LONGA EXTRACT ON BIOFILM FORMATION BY STREPTOCOCCUS MUTANS
}

\author{
GOKUL G' ${ }^{1}$, GEETHA RV ${ }^{2}$ \\ ${ }^{1}$ Department of Microbiolgy, Saveetha Dental College, Chennai, Tamil Nadu, India. ${ }^{2}$ Department of Microbiology, Saveetha Dental College, \\ Chennai, Tamil Nadu, India. Email: gokul.guna.1997.g@gmail.com
}

Received: 27 February 2017, Revised and Accepted: 13 April 2017

\section{ABSTRACT}

Objective: To find the effect of Curcuma longa extract on biofilm formation by Streptococcus mutans.

Methods: The organism S. mutans was isolated from saliva sample using special media (Mutans - sanguis agar) and maintained in tryptone soya agar at $4^{\circ} \mathrm{C}$ in Department of Microbiology, Saveetha Dental College and Hospitals.

Results: From the study, we infer that $78.35 \%$ of inhibition of the biofilm formation is seen with 100 ug of curcumin extract. From the result, it is evident that curcumin has a very good inhibitory effect on $S$. mutans growth.

Conclusion: The study concludes the inhibitory action of curcumin on $S$. mutans by preventing biofilm formation.

Keywords: Curcuma, Streptococcus mutans, Biofilm.

(C) 2017 The Authors. Published by Innovare Academic Sciences Pvt Ltd. This is an open access article under the CC BY license (http://creativecommons. org/licenses/by/4. 0/) DOI: http://dx.doi.org/10.22159/ajpcr.2017.v10i7.18161

\section{INTRODUCTION}

Streptococcus mutans is one of the main causative agents for dental caries, and thereby, studies are being done inhibiting its growth in the oral cavity by usage of different antibacterial agents. Many members of the genus Streptococcus that cause infections in humans use quorumsensing systems which help to regulate several physiological properties, including incorporating foreign DNA, resisting acids, forming biofilms, and becoming virulent [1]. The dental plaque biofilm grows on all surfaces in the oral cavity, including the teeth, mucosa, and all inserted materials. Dental restoration materials are widely used in the treatment of dental caries [2]. The biofilm can shear off, multiply, disperse, and colonize as planktonic individuals causing relapse and chronic infection, which become a major concern for public health [3]. S. mutans produces glucosyltransferase enzymes that synthesize glucan from the glucose moiety of sucrose that causes the cariogenicity of the dental pathogens [4]. Herbal medicines are more effective and less harmful as they have negligible side effects and show low mammalian toxicity $[5,6]$. Curcuma longa is a rhizome of ginger family which is native of the South Asia and has a long history of usage from dying to medicinal products. It is also found to have been used in traditional cooking. The beststudied compound is curcumin, which constitutes $3.14 \%$ (on average) of powdered turmeric [7]. Both curcumin and the oil fraction suppress the growth of several bacteria such as Streptococcus, Staphylococcus, and Lactobacillus [8], and aqueous extract of turmeric has also shown antibacterial effects [9]. Turmeric oil is also found to have antifungal effects on Aspergillus flavus and Aspergillus parasiticus [10]. This study is done in order to verify the antibacterial effects of Curcuma longa on S. mutans.

\section{METHODS}

The organism $S$. mutans was isolated from saliva sample using special media (Mutans - sanguis agar) and maintained in tryptone soya agar at $4^{\circ} \mathrm{C}$ in Department of Microbiology, Saveetha Dental College and Hospitals.

\section{Methodology}

Overnight, grown cultures of $S$. mutans from agar plates were inoculated in tryptone soya broth and incubated at $37^{\circ} \mathrm{C}$. Individual wells of sterile polystyrene 96 well flat bottom microtiter plates were filled with $200 \mu \mathrm{l}$ of culture suspension of the test organism. Uninoculated liters of the curcumin was added from the prepared stock solution of 10, 20, 40,80 , and $100 \mu \mathrm{g} / \mathrm{ml}$, respectively, and incubated at $37^{\circ} \mathrm{C}$ for $24 \mathrm{hrs}$. After incubation, content in the wells was removed, washed with $0.2 \mathrm{ml}$ phosphate buffer saline to remove free-floating bacteria. The adherence of the bacteria was fixed with sodium acetate (2\%) and stained with crystal violet. The crystal violet was removed, and $250 \mu \mathrm{l}$ of acetone was placed in each well to release the crystal violet. Then, finally, the readings were taken. Optical density (OD) of stained adherent bacteria was determined with an enzyme-linked immunosorbent assay reader (Bio-Rad) at wavelength $570 \mathrm{~nm}$. These OD values were taken as index of bacteria adhering the surface and formed biofilm. The experiment was carried out in triplicate, and their mean was taken for the analysis.

\section{RESULTS}

On addition of $100 \mathrm{ug} / \mathrm{ml}$ curcumin extract into the culture plates of S. mutans, it shows $78.35 \%$ of inhibition of the biofilm formation. (Graph 1) (Table 1) From the result, it is evident that curcumin has a very good inhibitory effect on $S$. mutans growth (Table 2).

\section{DISCUSSION}

Since curcumin has good inhibitory effects of $S$. mutans, it is recommended to be an important constituent of toothpastes and oral aids as $S$. mutans is a dangerous causative agent of dental caries and helps prevent growth in the oral cavity. Curcumin [1, 7-bis (4-hydroxy3-methoxyphenyl)-1, 6-heptadiene-3, 5-dione; diferuloylmethane], a yellow bioactive pigment, is the major component of turmeric which is a dried rhizome and is a rich source of beneficial phenolic compounds [11]. Curcumin is described as prebiotic, which can have beneficial effects on human health [12]. Other research data have showed that the curcuminoids may be effective in controlling dental biofilms and dental cavity formations, suggested that turmeric extracts can be extensively used in the treatment premalignant lesions in the oral cavity [13]. These antibiotics are sometimes associated with adverse effects on the host including hypersensitivity, immunosuppression, and allergic reactions which leads, there is a significant demand to develop 


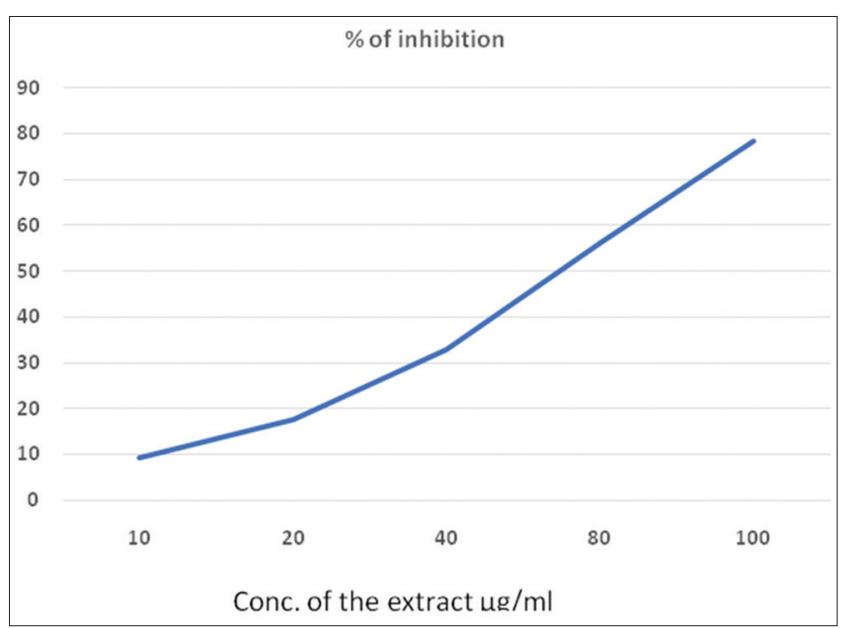

Graph 1: Percentage inhibition versus concentration of extract

Table 1: Biofilm formation and its OD values

\begin{tabular}{lll}
\hline Mean OD values & Adherence & Biofilm formation \\
\hline$<0.120-0.240$ & Non & Non/weak \\
$0.120-0.240$ & Moderately & Moderate \\
$>0.240$ & Strong & High \\
\hline
\end{tabular}

OD: Optical density

Table 2: Inhibition percentage with increase in concentration of curcumin

\begin{tabular}{ll}
\hline Concentration of the extract $\mathbf{u g} / \mathbf{m l}$ & Percentage of inhibition \\
\hline 10 & 09.15 \\
20 & 17.37 \\
40 & 32.90 \\
80 & 56.05 \\
100 & 78.35 \\
\hline
\end{tabular}

an alternative antimicrobial drug for the treatment of infectious diseases from medicinal plants $[14,15]$. It was found that the anti-adhesive effect of curcumin against $S$. mutans is mediated through collagen and fibronectin. These results support the widespread use of curcumin as a food-based antimicrobial agent [16]. S. mutans could outcompete other species, and occupy additional regions of the mouth, and cause advanced dental plaques, which can be as acidic as $\mathrm{pH} 4.0$ [17]. At $1 \%$ concentration, curcumin nanoparticles (curc NPs) have significant antimicrobial activity against cariogenic bacteria with not much adverse effects. However, the insolubility of curc NPs remains a major disadvantage [18]. The antibacterial activity of curcumin is credited to the destruction of peptidoglycan cell wall of bacteria [19]. Turmeric mouthwash can be effectively used as an adjunct to mechanical plaque control methods as $10 \mathrm{mg}$ of curcumin can be dissolved in $100 \mathrm{ml}$ distilled water, and the flavor may be enhanced by using peppermint oil [20]. The killing effect was shown to be dependent on curcumin concentration, radiant exposure, post-irradiation incubation time, bacteria species, and pharmaceutical preparation [21].

\section{CONCLUSION}

Thus, from the current study, curcumin is found to have very good anti-bacterial effect on $S$. mutans and can be advised to be in prevention of dental caries and also in endodontic procedures.

\section{REFERENCES}

1. Cvitkovitch DG, LiYH, Ellen RP. Quorum sensing and biofilm formation in Streptococcal infections. J Clin Invest 2003;112(11):1626-32.

2. Ferracane JL. Resin composite - State of the art. Dent Mater 2011;27(1):29-38

3. Thomas JE, Gibson GR, Darboe MK, Dale A, Weaver LT. Isolation of Helicobacter pylori from human faeces. Lancet 1992;340(8829): 1194-5.

4. Ogawa A, Furukawa S, Fujita S, Mitobe J, Kawarai T, Narisawa N, et al. Inhibition of Streptococcus mutans biofilm formation by Streptococcus salivarius Fru A. Appl Environ Microbiol 2011;77(5):1572-80.

5. Evans CE, Banso A, Samuel OA. Efficacy of some nupe medicinal plants against Salmonella typhi: An in vitro study. J Ethnopharmacol 2002;80(1):21-4.

6. Ahmad I, Mehmood Z, Mohammad F. Screening of some Indian medicinal plants for their antimicrobial properties. J Ethnopharmacol 1998;62(2):183-93.

7. Tayyem RF, Heath DD, Al-Delaimy WK, Rock CL. Curcumin content of turmeric and curry powders. Nutr Cancer 2006;55(2):126-31.

8. Bhavani Shankar TN, Sreenivasa Murthy V. Effect of turmeric (Curcuma longa) fractions on the growth of some intestinal and pathogenic bacteria in vitro. Indian J Exp Biol 1979;17(12):1363-6.

9. Arun N, Nalini N. Efficacy of turmeric on blood sugar and polyol pathway in diabetic albino rats. Plant Foods Hum Nutr 2002;57(1):41-52.

10. Jayaprakasha GK, Negi PS, Anandharamakrishnan C, Sakariah KK. Chemical composition of turmeric oil - A byproduct from turmeric oleoresin industry and its inhibitory activity against different fungi. Z Naturforsch C 2001;56(1-2):40-4.

11. Menon VP, Sudheer AR. Antioxidant and anti-inflammatory properties of curcumin. Adv Exp Med Biol 2007;595:105-25.

12. Panesar PS, Kumari S, Panesar R. Biotechnological approaches for the production of prebiotics and their potential applications. Crit Rev Biotechnol 2013;33(4):345-64.

13. Pandit S, Kim HJ, Kim JE, Jeon JG. Separation of an effective fraction from turmeric against Streptococcus mutans biofilms by the comparison of curcuminoid content and anti-acidogenic activity. Food Chem 2011;126(4):1565-70.

14. Clark AM. Natural products as a resource for new drugs. Pharm Res 1996;13(8):1133-44.

15. Cordell GA. Biodiversity and drug discovery - A symbiotic relationship. Phytochemistry 2000;55(6):463-80.

16. Song J, Choi B, Jin EJ, Yoon Y, Choi KH. Curcumin suppresses Streptococcus mutans adherence to human tooth surfaces and extracellular matrix proteins. Eur J Clin Microbiol Infect Dis 2012;31(7):1347-52

17. Takahashi N, Nyvad B. The role of bacteria in the caries process: Ecological perspectives. J Dent Res 2010;90(3):294-303.

18. Baghaeian P, Sodagar A, Bahador A, Pourhajibagher M, Ahmadi B. Effect of addition of curcumin nanoparticles on antimicrobial property and shear bond strength of orthodontic composite to bovine enamel. J Dent Tehran Univ Med Sci 2016;13(5):373-82.

19. Moghadamtousi SZ, Kadir HA, Hassandarvish P, Tajik H, Abubakar S, Zandi K. A review on antibacterial, antiviral, and antifungal activity of curcumin. Biomed Res Int 2014;2014:186864.

20. Devaraj SD, Neelakantan P. Curcumin-pharmacological actions and its role in dentistry. Asian J Pharm Res Health Care 2014;6(1):19-22.

21. Neelakantan P, Jagannathan N, Nazar N. Ethnopharmacological approach in endodontic treatment: A focused review. Int J Drug Dev Res 2011;3(4):68-77. 